\title{
BITCOIN - AN INNOVATIVE PAYMENT METHOD WITH A NEW TYPE OF INDEPENDENT CURRENCY
}

\author{
T. Todorov* \\ Department of Economics, Faculty of Economics, Trakia University Stara Zagora, Bulgaria
}

\begin{abstract}
Bitcoin is a type of crypto-currency that was launched in January 2009 as an emerging digital phenomenon in the financial technology realm by an unknown computer scientist using the pseudonym Satoshi Nakamoto. It is an innovative and independent currency that uses cryptography for its creation and for performing secure transactions. The aim of this article is targeted to introducing into the bitcoin's technology. The survey results and empirical research show that despite the bitcoin benefits over the currency of central authority people do not believe in this crypto-currency because of its speculative character.
\end{abstract}

Key words: bitcoin, crypto-currency, Blockchain, virtual currency, money

\section{INTRODUCTION}

Bitcoin is an extremely interesting example of innovation and online co-work. Bitcoin is a virtual currency, or a form of crypto-currency with its origins dating back to beginning of 2008 , it exploit cryptography in its creation, transactions and security. Satoshi Nakamoto is the pseudonym of an anonymous programmer which is the founder of Bitcoin. Many people believed one of the motive in the creation of the virtual currency was the 2008 financial crisis. Bitcoin was produced to eliminate fiscal responsibility and trust from governments, central banks and other third parties, removing the peril of the inflationary whims and other economic tools employed by central banks and governments. Bitcoins are available to be purchased through online exchanges, nonetheless many people choose to mine for them. Mining for Bitcoins is obtained through a mathematical process using powerful computer GPUs or dedicated mining rigs. The amount of bitcoins is defined to be exactly 21 million. When Bitcoins already mined or purchased they are stored in digital wallets, which are available as desktop software, mobile apps and web wallets. Regardless using cryptography, security issues remain a cause for anxiety. Despite the fact that there are much of cryptocurrencies in active use today, Bitcoin is by far the most attractive and widely used. $(1,2,3)$

\footnotetext{
*Correspondence to: Todor Todorov, Department of Economics, Trakia University, Stara Zagora, Bulgaria, e-mail:todoroft@gmail.com
}

\section{BLOCK CHAIN}

A main innovation of virtual currency systems is the use of a public ledger called the "block chain" that allows payments to be made in a decentralized way. Bitcoin's block chain is fundamental to its operation. The block chain is a distributed, public ledger of all previous Bitcoin transactions, which are stored in groups known as blocks. Every node of Bitcoin's software network - the server farms and terminals, run by individuals or groups known as miners, whose endeavor to yield new Bitcoin units result in the recording and confirmation of Bitcoin transactions, and the periodic formation of new blocks - contains an identical record of Bitcoin's block chain. Because new Bitcoin transactions steadily appear, the Bitcoin block chain, though with limited supply, grows over time. As long as miners proceed their work and record recent transactions, the Bitcoin block chain will always be a work in progress. In other words, there's no prearranged length at which the block chain will stop growing. Typically, miners create a new block chain, which includes all prior transactions and a new transaction block, every 10 minutes. Every two weeks, Bitcoin's source code is projected to adjust to the amount of mining power dedicated to creating new block chains, conserving the 10-minute average creation interval. If mining power increased during the most recent two-week interval, new block chains become more difficult to create during the following two-week interval. If mining 
power decreases, new chains become easier to create. Bitcoin's block chain is the exclusive moderator of Bitcoin ownership - no complete record exists anywhere else. The block chain also operate as a payment processing system, like Visa or PayPal, with the miners working as the system's employees. A Bitcoin transaction hasn't technically occurred until it's added to the block chain, at which point it becomes irreversible - unlike traditional payment processors. Bitcoin also doesn't have any standardized system for refunds. During the window between the transaction itself and the moment it's added to the block chain, the respective Bitcoin units are actually held in the middle - they can't be used by either party to the transaction. This suspend duplicate transactions, known as double-spending, and protects the system's principle. (4)

\section{MINING}

Mining is the process of appending transaction records to Bitcoin's public ledger of past transactions which is named Blockchain as it is a chain of blocks. The block chain works to confirm transactions to the rest of the network as having taken place. Bitcoin nodes use the block chain to differentiate legitimate Bitcoin transactions from attempts to double-spend coins that have already been spent elsewhere. Mining is consciously designed to be resourceintensive and difficult so that the number of blocks found each day by miners remains steady. Individual blocks must contain a proof of work to be considered valid. This proof of work is confirmed by other Bitcoin nodes each time they receive a block. Bitcoin uses the hashcash proof-of-work function. The fundamental purpose of mining is to allow Bitcoin nodes to reach a secure, counterfeitresistant agreement. Mining is also the method used to introduce Bitcoins into the system: Miners are paid any transaction fees as well as a "reward" of newly created coins. This both serves the purpose of spread new coins in a decentralized way as well as motivate people to provide security for the system. (5) Bitcoin mining is so called because it match the mining of other commodities: it requires effort and it slowly makes new currency available at a rate that match the rate at which commodities like gold are mined from the ground. (6)

\section{BITCOIN WALLETS}

In order to store, spend and transfer a user's mined or purchased Bitcoins, user's needs a Bitcoin wallet which is actually a virtual „wallete ${ }^{\text {ee }}$ or ,safe-deposit box ${ }^{\text {ee }}$. There are three different types of Bitcoin wallets available to users, software, hardware wallets, and web wallets.(1) Though wallets theoretically protect against the theft of Bitcoin units that aren't currently being used, they're vulnerable to hacking - especially public wallets used by Bitcoin exchanges, online marketplaces, and specialized websites that exist solely to store Bitcoin wallets known as "web wallet services". (4)

\section{BITCOIN EXCANGES}

Bitcoin exchange companies allow users to exchange Bitcoin units for fiat currencies, such as the U.S. dollar and euro, at volatile exchange rates. Many Bitcoin exchanges also exchange Bitcoin units for other cryptocurrencies, including less popular alternatives that can't directly be exchanged for fiat currencies. Most Bitcoin exchanges have a fee, typically less than $1 \%$, of each transaction's value. Bitcoin exchanges ensure that the Bitcoin market remains liquid, setting their value relative to traditional currencies and allowing holders to profit from speculation on fluctuations in that value. That said, Bitcoin users must understand that Bitcoin's value is subject to turbulent changes - weekly moves of $50 \%$ in either direction have exist in the past. Such fluctuations are unheard of among stable fiat currencies. (4).

\section{SURVEY ANALYSIS}

An online poll was held between 17 January 2017 and 17 May 2017 involved a total of 50 people, including 25 men and 25 women. $76 \%$ of all respondents are youngsters between 19 and 30 years of age. The rest of the respondents are almost proportionally distributed by age groups up to 60 years of age and over. $44 \%$ and $48 \%$ of respondents said they live in a large and medium-sized city respectively. $56 \%$ of respondents have completed secondary education and $28 \%$ have a Bachelor's degree. The people who are studying are $42 \%$, the people who work - $26 \%$ and the people who work and study are $24 \%$. Regarding income, $76 \%$ of respondents are defined as middle income earners. $66 \%$ responded that they had a slight perception of bitcoin, while $34 \%$ did not know what it was and understood the existence of this phenomenon from this survey. $70 \%$ responded that they still do not use bitcoin, $28 \%$ said they did not intend to use it, and only one person claimed to use bitcoin. $80 \%$ of respondents are of the opinion that bitcoin will not replace the current fiat currencies controlled by governments. Analyzing the survey results, young people who study or work, populate large cities, and defined themselves as middleincome earners, know or at least once have heard the term Bitcoin. About $70 \%$ of them say 
they are not using Bitcoin, but the rest of the respondents would never use Bitcoin. $80 \%$ of all the people who participated in the poll support the view that Bitcoin will not replace normal money. This group includes people who do not know what is Bitcoin, but the majority are know about existence and do not trust this speculative e-currency. (Table 1)

Table 1. Survey

\begin{tabular}{|l|l|}
\hline What is your gender? & Count \\
\hline Female & 25 \\
\hline Male & 25 \\
\hline & \\
\hline How big is the place where you lives? & Count \\
\hline Big city & 22 \\
\hline Small town & 3 \\
\hline Village & 1 \\
\hline Mid-sized city & 24 \\
\hline & \\
\hline What is your age? & Count \\
\hline 19 - 30 years & 38 \\
\hline 31 - 40 years & 3 \\
\hline 41 - 50 years & 5 \\
\hline 51 - 60 years & 2 \\
\hline 60+ years & 2 \\
\hline & \\
\hline What degree of education do you have? & Count \\
\hline Bachelor's degree & 14 \\
\hline Master's degree & 3 \\
\hline Primary education & 1 \\
\hline Professional Bachelor & 4 \\
\hline Secondary education & 28 \\
\hline & \\
\hline Social Status? & Count \\
\hline Unemployed & 2 \\
\hline Retiree & 2 \\
\hline Worker & 13 \\
\hline Student & 21 \\
\hline Working student & 12 \\
\hline & \\
\hline What is your incomes? & Count \\
\hline High incomes & 2 \\
\hline Low incomes & 10 \\
\hline Middle incomes & 38 \\
\hline & \\
\hline Do you know what a Bitcoin is? & Count \\
\hline Yes I know & 20 \\
\hline No & 17 \\
\hline I have heard about it & 13 \\
\hline & \\
\hline Are you using Bitcoin? & Count \\
\hline Not yet & 35 \\
\hline Yes & 1 \\
\hline Not yet and I would not use it & 14 \\
\hline & \\
\hline Do you think Bitcoin can replace fiat currencies? & Count \\
\hline Yes & 40 \\
\hline No & \\
\hline & \\
\hline & \\
\hline & \\
\hline & \\
\hline & \\
\hline
\end{tabular}

\section{EMPIRICAL ANALYSIS}

In the following empirical analysis is presented the relation between the interest of new users or potential investors and bitcoin price. The data for the price of Bitcoin was taken from the market price chart on
Blockchain. Bitcoin market price chart is available in CVS form to download from Blockchain website. The data provided information about the market price of Bitcoin in USD for every day. The data from CVS file are imported in Microsoft Excel and the 
results used in empirical analysis were calculated as average value for a week. The time frame is January 18th 2015 until January 14th 2017.

The term visibility (of Bitcoin) is used to denote the intensity of the interest of general public (in Bitcoin). The empirical data used for visibility was obtained through Google Trends. Google Trends is a metric provided by Google denoting how many times people used the Google search engine to search for a particular term. In this case, the term was "Bitcoin". Google provides the data with a weekly granularity (one data point per week), and is normalised so that the peak value is always 100. The output of Google Trends was downloaded as a CSV file and imported into a Microsoft Excel. The time frame is January 18th 2015 until January 14th 2017.(7)

The calculation of correlation between price and visibility is made in Microsoft Excel.
The result of correlation coefficient is 0.81 and the scatter plot diagram including a bestfit line are presented in Table 2. The analysis shows a very strong positive correlation between Bitcoin price in USD and visibility (measured in terms of number of Bitcoin searches in Google). In other words, the price of Bitcoin correlates with the public interest in Bitcoin. The created hype of rising price of Bitcoin rise the attractiveness of that currency and motivates people's interest in Bitcoin. Rising interest in Bitcoin results in excessive buying of Bitcoin and the price is driving up. Rising interest and rising price mutually influence each other. Bitcoin is a relatively new currency, its price formation is not well understood yet. It is attractive for some investors because its price volatility from which they could make a good profit.

Table 2. Scatter plot diagram of price and visibility, weekly range

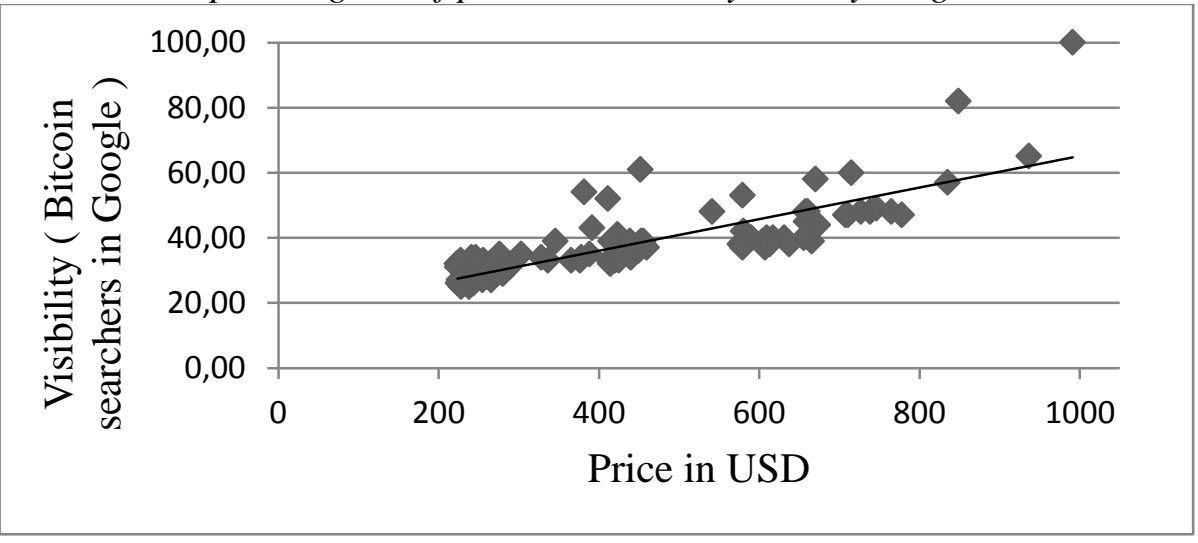

\section{CONCLUSIONS}

The fluctuation of Bitcoin's value also adds to its risk of using that new type of currencies. Bitcoin is not fixed to any real-world currency. Its value is determined by laws of supply and demand and trust and believing in the system. This has force to Bitcoin being used more as a speculative investment tool than a currency or payment system. Bitcoins are also not resistant to fraud. As of November 2013, approximately 850,000 bitcoins have been stolen from Mt. Gox exchange company. Since all Bitcoin transactions are irreversible, there is no helping tool for users who suspect they are or have been the victim of fraud. One can argue that consumers now have a choice: either pay higher fees for services that offer chargeback and refunds services in the case of fraud or pay lower fees for services with little to no recourse.

\section{REFERENCES}

1. Bitcoin: Pseudo-currency or the future?, Market Line Case Study, 2013
2. Bitcoin: speculative bubble or currency of the future?, Antonio Escoda, Economic Analysis Unit, Research Department, "la Caixa"

3. Can Bitcoin Compete with Money?, Beat Weber, http://peerproduction.net/issues/issue-4value-and-currency/invited-comments/canbitcoin-compete-with-money/

4. What Is Bitcoin - History, How It Works, Pros \& Cons, Brian Martucci, http://www.moneycrashers.com/bitcoinhistory-how-it-works-pros-cons/

5. What is Bitcoin Mining? https://www.bitcoin.com/bitcoin-mining/

6. What is Bitcoin Mining? https://www.weusecoins.com/en/miningguide/

7. Economics of Bitcoin: is Bitcoin an alternative to fiat currencies and gold?, Surda, P., pp. 50-54. 